\title{
The Fire Growth Rate in a Ventilated Tunnel Fire
}

\author{
YING ZHEN LI, and HAUKUR INGASON \\ SP Technical Research Institute of Sweden \\ Box 857, SE-501 15 Borås, Sweden
}

\begin{abstract}
Increasing longitudinal ventilation velocity enhances the heat transfer from hot gases to fuel and then results in an increase of the fire growth rate in a tunnel fire. However, the effect of ventilation on the flame spread and the fire growth rate has not been fully explored. In this paper the relationship between the flame spread and the fire growth rate in a ventilated flow was analyzed theoretically. A large amount of data relevant to the fire growth rate from model and full-scale tunnel fire tests was collected and applied to a detailed analysis of the effect of ventilation on the fire growth rate. The thermal inertia, heat of combustion, the wet perimeter, and the mass burning rate per unit area of the fuel play important roles in the fire growth rate. In addition, the fire growth rate increases linearly with the ventilation velocity. A correlation that fits all the data of the fire growth rate from model and full-scale tunnel fire tests very well was proposed.
\end{abstract}

KEYWORDS: tunnel fires, fire growth, flame spread, longitudinal ventilation.

\section{NOMENCLATURE LISTING}

\begin{tabular}{|c|c|c|c|}
\hline$A_{f}$ & burning fuel surface area $\left(\mathrm{m}^{2}\right)$ & Greek & \\
\hline$c$ & heat capacity $(\mathrm{kJ} / \mathrm{kg} \cdot \mathrm{K})$ & $\rho$ & density $\left(\mathrm{kg} / \mathrm{m}^{3}\right)$ \\
\hline$C_{f}$ & material property defined in Eq. 18 & $\delta$ & characteristic depth (m) \\
\hline$C_{k}$ & coefficient in Eq. 1 & $\Delta$ & Distance (m) \\
\hline$g$ & gravity acceleration $\left(\mathrm{m} / \mathrm{s}^{2}\right)$ & $\eta$ & combustion efficiency \\
\hline$H$ & tunnel height $(\mathrm{m})$ & $\phi$ & correlation coefficient between spread \\
\hline$\Delta H_{c}$ & heat of combustion $(\mathrm{kJ} / \mathrm{kg})$ & & rate and ventilation velocity \\
\hline$k$ & thermal conductivity $(\mathrm{kJ} /(\mathrm{m} \cdot \mathrm{s} \cdot \mathrm{K}))$ & \multicolumn{2}{|c|}{ subscripts } \\
\hline$k \rho c$ & thermal inertia $\left(\mathrm{kW}^{2} \cdot \mathrm{s} \cdot \mathrm{m}^{-4} \cdot \mathrm{K}^{-2}\right)$ & $a$ & air \\
\hline$l$ & characteristic length (m) & $c$ & convective \\
\hline$\dot{m}_{f}^{\prime \prime}$ & fuel burning rate per unit area $\left(\mathrm{kg} / \mathrm{m}^{2} \cdot \mathrm{s}\right)$ & $d s$ & downstream \\
\hline$N u$ & Nusselt number & $f$ & fuel \\
\hline$Q$ & heat release rate $(\mathrm{kW})$ & $F$ & flame \\
\hline$\dot{q}^{\prime \prime}$ & heat flux $\left(\mathrm{kW} / \mathrm{m}^{2}\right)$ & $i$ & the $i^{\text {th }}$ fuel \\
\hline $\operatorname{Re}$ & Reynolds number & $i g$ & ignition \\
\hline$t$ & time $(s)$ & $r$ & radiative \\
\hline$T$ & gas temperature $(\mathrm{K})$ & & upstream \\
\hline$\Delta T$ & excess gas temperature $(\mathrm{K})$ & \multicolumn{2}{|c|}{ superscripts } \\
\hline$u_{o}$ & ventilation velocity $(\mathrm{m} / \mathrm{s})$ & $*$ & dimensionless \\
\hline$V$ & flame spread rate $(\mathrm{m} / \mathrm{s})$ & $"$ & per square meter \\
\hline$w_{p}$ & wet perimeter of the fuel (m) & . & per second \\
\hline$x$ & length (m) & & \\
\hline
\end{tabular}

\section{INTRODUCTION}

Interest in fire safety issues in tunnels has increased dramatically owing to numerous catastrophic tunnel fires and the extensive monitoring of these incidents in the media. A common feature in all of these fires has been the significance of the fire load and of ventilation for the growth of the fire. In several of the fires, the type of load being carried by goods vehicles played an important part in determining the severity of the fire. The main reasons for this are that heavy goods vehicles (HGVs) consist of, or carry, highly flammable 
materials, and that the fire spreads very rapidly due to the longitudinal ventilation in the tunnel. Although the ventilation velocity may probably result in an increase of the heat release rate (HRR) and the fire growth rate, the forced longitudinal ventilation is important and necessary to prevent the smoke backflow in a tunnel fire. Much research on critical velocities, defined as the minimum longitudinal ventilation velocity to prevent the smoke backflow, and on the back-layering length under lower ventilation, has been done in the past decades [1-3].

The effect of longitudinal ventilation on the fire growth rate in HGV fires is an important issue, however, has not yet been known clearly. There is still no good theory to express the relationship between them. The common knowledge is that the fire growth rate increases with the ventilation velocity in a tunnel fire. In previous research, the effects of ventilation and tunnel geometry on the fire growth rate are focused on. For example, Carvel et al. [4] investigated the interaction of the ventilation flow with the fire growth rate in a tunnel fire. The results are probabilistic in nature. A Bayesian probabilistic approach was used to refine estimates, made by a panel of experts, with data from experimental fire tests in tunnels. Their conclusions were, however, based on rather limited experimental data.

Actually, the fire growth rate in a ventilated tunnel fire should be related to the flame spread over the fuel surface. There has been much research on the flame spread over a solid surface, especially over a vertical combustible wall. Basic equations controlling the process are identified. The forced airflow enhances the flame spread at a low ventilation velocity and gradually shows cooling effect on the flame spread at a high ventilation velocity, but how the flow affects the spread is not clearly known, see Ref. [5]. Thomas [6] proposed an approximate formula applicable to wild fires, wood cribs and urban conflagration which can be expressed as follows:

$V \rho_{f}=C_{k}\left(1+u_{o}\right)$

where $C_{k}$ is a coefficient as 0.07 for wildland fires and 0.05 for wood cribs.

In a tunnel fire, the longitudinal ventilation plays a key role in the flame spread, thus it is much different with an open fire or a room fire. Moreover, the relationship between the fire growth rate and the flame spread over the fuel surface in a ventilated tunnel fire is not clearly known yet.

This paper theoretically analyzes the relationship between the flame spread and the fire growth rate in a ventilated flow. A large amount of data relevant to the fire growth rate from model and full scale tunnel fire tests was collected and applied to a detailed analysis of the fire growth rate.

\section{MODEL OF FIRE GROWTH RATE IN A VENTILATED FLOW}

A schematic diagram of flame spread over a solid surface is shown in Fig. 1. The temperature in each control volume close to the pyrolysis zone increases gradually due to heat feedback from the flame and the hot gases until it reaches the ignition value where it starts to burn.

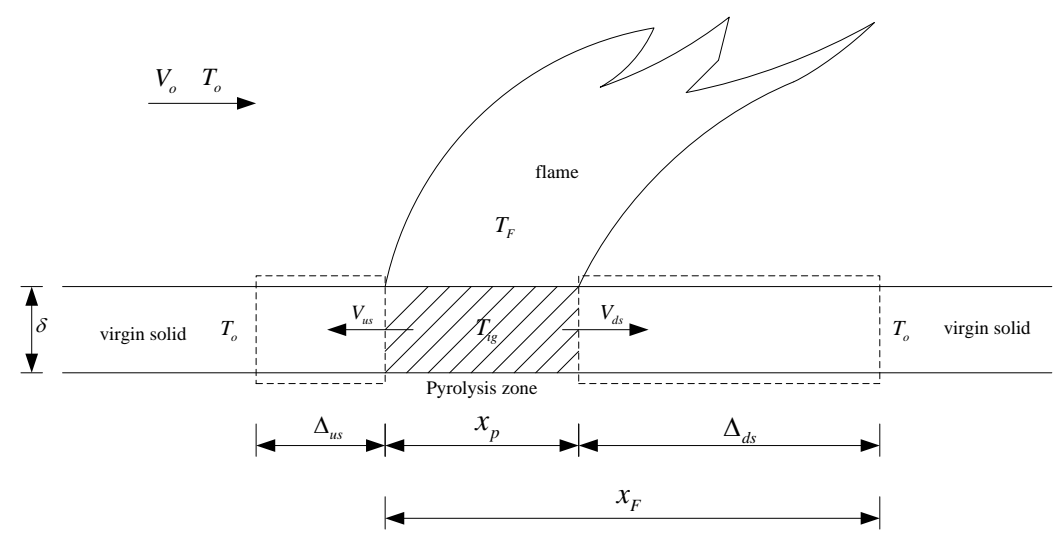

Fig. 1. A schematic diagram of flame spread over a solid surface. 
The energy equations for the control volumes upstream and downstream can be expressed as [7]:

$\rho_{f} c_{f} \delta\left(T_{i g}-T_{o}\right) V=\dot{q}^{\prime \prime} \Delta$

where

$\delta \approx \sqrt{\frac{k_{f} t}{\rho_{f} c_{f}}}, \quad t=\frac{\Delta}{V}$

It can be transformed into:

$V=\frac{\dot{q}^{\prime \prime 2} \Delta}{(k \rho c)_{f}\left(T_{i g}-T_{o}\right)^{2}}$

Therefore the flame spread rate is intimately related to the heat flux and the distance $\Delta$.

\section{Opposed Flow Spread (Upstream)}

In a tunnel fire, the type of flame spread upstream of the fire source is the opposed flow spread. The forward flame heat flux upstream of the fire can be characterized as conduction in the gas phase which suggests [7]:

$\dot{q}^{\prime \prime}=k_{a} \frac{T_{f}-T_{o}}{\Delta}$

Since the forward conduction in the gas phase dominates the heat transfer, the conduction must be balanced with convection which suggests:

$\rho_{a} c_{a} u_{o} \frac{\partial T}{\partial x} \approx k_{a} \frac{\partial^{2} T}{\partial x^{2}}$

This suggests:

$\Delta \approx \frac{k_{a}}{\rho_{a} c_{a} u_{o}}$

Combining all these equations we obtain:

$V_{u s}=\frac{(k \rho c)_{a}\left(T_{F}-T_{o}\right)^{2}}{(k \rho c)_{f}\left(T_{i g}-T_{o}\right)^{2}} u_{o} \propto \frac{1}{(k \rho c)_{f}} u_{o}$

This means the flame spread rate upstream of the fire linearly increases with the ventilation velocity.

\section{Wind-aided Spread (Downstream)}

In a tunnel fire, the flame spread downstream of the fire source is the type of wind-aided spread. The same equation, i.e., Eq. 3, can be obtained in such cases, but with different interpretation of the heat flux from the flame and the distance $\Delta$.

The heat conduction through the thermally-thick fuel, i.e. heat transfer to the fuel surface by heat convection and radiation, rather than the conduction in the gas phase, are the dominant modes for the wind- 
aided spread downstream. Therefore the heat flux from the flame downstream of the fire can be expressed as:

$\dot{q}^{\prime \prime}=\dot{q}_{c}^{\prime \prime}+\dot{q}_{r}^{\prime \prime}$

The radiative heat flux downstream could be reasoned to depend on the flame temperature which is intimately related to ambient oxygen concentration, given that the effect of the view factor due to different ventilation could be ignored. The convective heat flux in a turbulent flow can be expressed as follows:

$\dot{q}_{c}^{\prime \prime}=\frac{k}{l} N_{u} \Delta T \propto \mathrm{Re}^{0.8} \propto u_{o}^{0.8}$

Therefore the heat transfer from the flame downstream should be enhanced.

The fire plume is deflected in a ventilated flow. This suggests the distance $\Delta$ increases with the ventilation velocity. Note that this distance is related to the pyrolysis length that cannot be explicitly predicted.

According to the above analysis, it is known that the flame spread rate downstream of the fire increases with the ventilation velocity, which could be expressed:

$V_{d s} \propto u_{o}$

However, how the flame spread rate downstream of the fire varies with the ventilation velocity is not clearly understood.

The flame spread in a tunnel fire, $V$, is a combination of flame spread upstream, $V_{u s}$, and flame spread downstream, $V_{d s}$. Clearly, it is seen that in a tunnel fire both the flame spread upstream and downstream increases with the ventilation velocity. Based on Thomas' work and the above analysis, it can be assumed that the flame spread rate in a tunnel fire is proportional to the ventilation velocity.

Note that the flame spread rate is directly related to the properties of the fuel, i.e. inversely proportional to the thermal inertia, $k \rho c$ [5]. In addition, the surface orientation, air composition, atmospheric pressure and ignition temperature also have an influence on the flame spread. The air composition and atmospheric pressure will not be discussed here since they are normally ambient in our case. In addition, since the pilot ignition temperature for most of the commonly used solid fuels is in a range of $300{ }^{\circ} \mathrm{C}$ to $400{ }^{\circ} \mathrm{C}$, for simplicity it will also not be discussed here. The effect of the surface orientation of the fuel, which is difficult to estimate for a tunnel fire due to the complexity of the fuel configuration, will be implicitly considered with the aid of empirical constants.

Therefore the flame spread in a longitudinally ventilated tunnel fire can be approximately expressed as follows:

$V \propto \frac{1}{(k \rho c)_{f}} u_{o}$

There is a need to point out here that there is some evidence of a decreasing effect under high ventilation conditions, i.e. blow-off effect, since the cooling effect starts to dominate the combustion process under these conditions. However, it was not observed within the range of our tests and therefore it is not included in this study. It can be explained by the fact that the existing ventilation velocity in a tunnel fire is relatively low. 


\section{Relationship between Fire Growth Rate and Flame Spread Rate}

The heat release rate can be expressed as:

$Q(t)=\dot{m}_{f}^{\prime \prime} \eta \Delta H_{c} A(t)$

The mass loss rate per unit area is directly related to properties of the fuel, and heat transfer among the flame, hot gases, fuel and the tunnel walls. Ideal values were found by Tewarson and Pion [8] based on the assumption that all heat losses were reduced to zero or exactly compensated by an imposed heat flux equal to the total heat losses from the fire source. Ingason and Li [9] compared the maximum mass loss rates per unit area from tunnel fire tests to the ideal value of Douglas-fir and found that there is a good agreement between them. Here the mass loss rate per unit area is assumed to be a constant for a quasi-steady combustion process in a tunnel fire. Therefore the heat release rate is directly related to the burning area.

In a large tunnel fire, the longitudinal flame spread dominates the fire development. Therefore it is assumed that the fire is burnt over the whole cross-section, and then spreads longitudinally. In other words, the flame spread in a large tunnel fire is assumed to be one-dimensional flame spread, i.e. longitudinal flame spread. Therefore Eq. 12 can be transformed into:

$\frac{d Q}{d t}=w_{p} \dot{m}_{f}^{\prime \prime} \eta \Delta H_{c} V$

where $w_{p}$ is the wet perimeter of the fuel, i.e. the contact perimeter between fuel and gas in a cross-section.

Thus the fire growth rate in a large tunnel fire can be expressed in the following form:

$\frac{d Q}{d t} \propto \frac{\dot{m}_{f}^{\prime \prime} \eta \Delta H_{c}}{(k \rho c)_{f}} w_{p} u_{o}$

Equation 14 shows that the properties of fuel play important roles in the fire growth rate in a ventilated flow.

\section{Fuels Consisting of Several Parts}

If the fuel consists of several parts or layers with different materials, i.e. a combination of wood, plastic, and mattress, the heat release rate can be expressed as:

$Q(t)=\sum_{i=1}^{N} \dot{m}_{f, i}^{\prime \prime} \eta_{i} \Delta H_{c, i} A_{i}(t)$

The fire growth rate can be expressed as:

$\frac{d Q(t)}{d t}=\sum_{i=1}^{N} \eta_{i} \dot{m}_{f, i}^{\prime \prime} \Delta H_{c, i} w_{p, i} V_{i}(t)$

Equation 16 can be transformed into:

$\frac{d Q(t)}{d t} \propto u_{o} \sum_{i=1}^{N} \frac{\phi_{i} \eta_{i} \dot{m}_{f, i}^{\prime \prime} \Delta H_{c, i}}{(k \rho c)_{f, i}} w_{p, i}$

A material property of the $i^{\text {th }}$ fuel, $C_{f, i}$, is defined here: 
$C_{f, i}=\frac{\dot{m}_{f, i}^{\prime \prime} \Delta H_{c, i}}{(k \rho c)_{f, i}}$

For simplicity, it is assumed that the correlation coefficients $\phi_{i}$ for all the parts are the same, and the combustion efficiency is a constant. Then the fire growth rate can be simplified into:

$\frac{d Q(t)}{d t} \propto u_{o} \sum_{i=1}^{N} C_{f, i} w_{p, i}$

These results can be applied to the fire scenario in a ventilated flow. For a tunnel fire, the special geometry of tunnel and the vehicle do have influence on the fire growth rate, which thus needs to be analyzed in detail.

Several dimensionless parameters are defined here:

Dimensionless time:

$t_{o}^{*}=t \sqrt{g / H}$

Dimensionless heat release rate:

$Q^{*}=\frac{Q}{\rho_{o} c_{p} T_{o} g^{1 / 2} H^{5 / 2}}$

Dimensionless ventilation velocity:

$u_{o}^{*}=\frac{u_{o}}{\sqrt{g H}}$

Then the dimensionless fire growth rate, $d Q^{*} / d t^{*}$, can be transformed into:

$\frac{d Q^{*}}{d t^{*}} \propto \frac{u_{o}^{*}}{H^{3 / 2}} \sum_{i=1}^{N} C_{f, i} w_{p, i}$

If the fuel only consists of one material, Eq. 23 can be transformed into:

$\frac{d Q^{*}}{d t^{*}} \propto \frac{w_{p} u_{o}^{*}}{H^{3 / 2}}$

\section{DESCRIPTION OF RELEVANT TUNNEL FIRE TESTS}

Four series of model-scale tunnel fire tests and the Runehamar tunnel fire tests carried out by SP Fire Technology, and the Second Benelux tunnel fire tests carried out by TNO, are briefly described here. The data gathered from these tests will be used to verify the results of theoretical analysis in the following section.

The method of scaling being used in the model-scale tests is the most widely used Froude scaling. Clearly, it is impossible and not necessary to preserve all the terms obtained by scaling theory simultaneously in model scale tests. The terms that are most important and most related to the study can be preserved. The thermal inertia of the involved material, turbulence intensity and radiation are not explicitly scaled, but we scale the HRR, the time, the flow rates, the gas temperature, the energy content and the mass. In the model 
tunnel fire tests, there are always ventilated flows across the fire, which makes the flows and flames more turbulent. In our opinion, the scaling ratio should not be smaller than about 1:20 in order to preserve the Froude number and to avoid producing a laminar flow in the tunnel. Our experience of model tunnel fire tests in this scale shows there is a good agreement between model-scale and large-scale on many focused issues. Such kinds of scales are widely used in model tunnel fire tests all over the world. Information about scaling theories can be obtained from for example Refs. [9,10].

\section{Automatic Water Spray System Tests}

A total of 28 tests, including 3 free-burn tests, were carried out in a 1:15 scale model tunnel [11]. The main aim was to analyze the possibility of using an automatic water spray system instead of a deluge system in a tunnel fire. The fire spread between wood cribs with a free distance of $1.05 \mathrm{~m}(15.75 \mathrm{~m}$ in full scale) was also tested. Further, the effect of ventilation velocities and water flow rates on the activation of nozzles, heat release rate, fire growth rate, gas temperature, heat radiation and fire spread was investigated.

The tunnel itself was $10 \mathrm{~m}$ long, $0.6 \mathrm{~m}$ wide and $0.4 \mathrm{~m}$ high, as shown in Fig. 2. Average longitudinal velocities of $0.52 \mathrm{~m} / \mathrm{s}, 1.03 \mathrm{~m} / \mathrm{s}, 1.54 \mathrm{~m} / \mathrm{s}$ and $2.07 \mathrm{~m} / \mathrm{s}$, obtained by adjusting a frequency regulator, were used in the test series. The corresponding large-scale velocities were $2 \mathrm{~m} / \mathrm{s}, 4 \mathrm{~m} / \mathrm{s}, 6 \mathrm{~m} / \mathrm{s}$ and $8 \mathrm{~m} / \mathrm{s}$, respectively.

The fire load consisted of wood cribs (Pine), as given in Fig. 3. The weight of a wood crib is about $4.4 \mathrm{~kg}$. The free distance between each horizontal stick was $0.033 \mathrm{~m}$ and the total fuel surface area of a wood crib was estimated to be $1.37 \mathrm{~m}^{2}$. The estimated heat release rate is about $200 \mathrm{MW}$ in full scale.

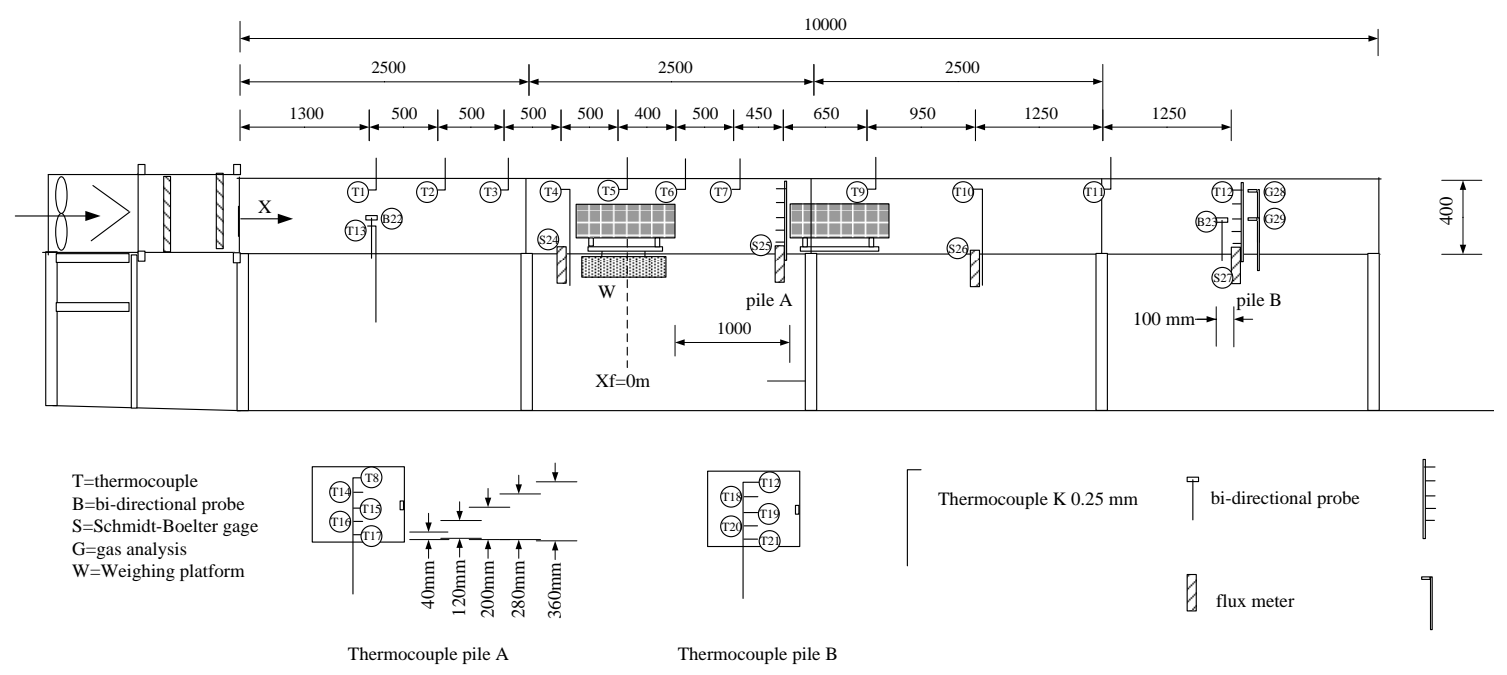

Fig. 2. The layout of instruments in the automatic water spray tests (dimensions in $\mathrm{mm}$ ).

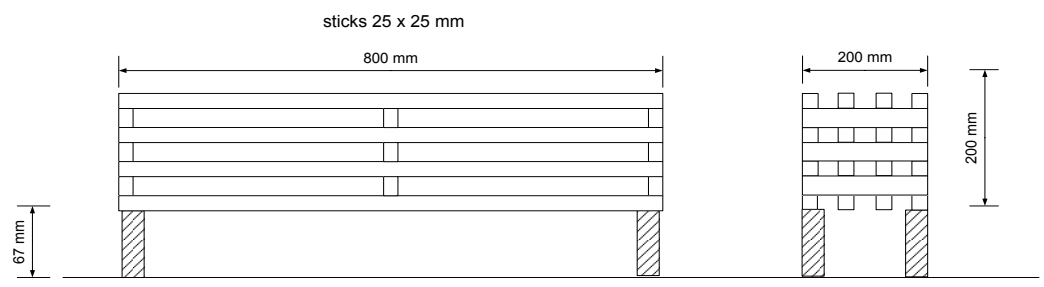

Fig. 3. Detailed drawing of the wood cribs in this series of tests.

\section{Longitudinal Ventilation Tests}

A total of 12 tests were carried out in a 1:23 scale model tunnel with longitudinal ventilation [9]. The fire load was simulated with the aid of wood cribs, corresponding to a scaled-down HGV fire load, and the fire 
spread between two or three wood cribs with a free distance of $0.65 \mathrm{~m}$ (about $15 \mathrm{~m}$ in full scale) was tested. The tunnel itself was $10 \mathrm{~m}$ long, $0.4 \mathrm{~m}$ wide and two heights of $0.3 \mathrm{~m}$ and $0.2 \mathrm{~m}$ was used respectively. The parameters tested were: the number of wood cribs, type of wood cribs, the longitudinal ventilation rate and the ceiling height. The fire spread between wood cribs, with a free distance corresponding to $15 \mathrm{~m}$ in full scale, was also tested. The effects of different ventilation rates on the fire growth rate, fire spread, flame length, gas temperatures and back-layering, were investigated.

\section{Point Extraction Ventilation Tests}

A total of 12 tests were carried out in a 1:23 scale model tunnel with point extraction ventilation $[12,13]$. The fire load was simulated with aid of wood cribs. The parameters tested were the longitudinal ventilation rate, the arrangement of the exhaust openings and the exhaust capacity. Moreover, the fire spread between wood cribs with a free distance of $0.65 \mathrm{~m}$ (about $15 \mathrm{~m}$ in full scale) was tested. The point extraction ventilation system was tested under different fire and flow conditions using either forced longitudinal ventilation or natural ventilation. The tunnel itself was $10 \mathrm{~m}$ long, $0.4 \mathrm{~m}$ wide and $0.2 \mathrm{~m}$ high. The study focuses on single and two point extraction systems. The maximum heat release rate, fire growth rate, maximum excess temperature beneath the ceiling, flame length and heat flux were analyzed using relationships obtained from theoretical considerations.

\section{Tunnel Cross-section Tests}

A total of 42 tests were performed in model tunnels with longitudinal ventilation to study the effect of the height and width of a tunnel on the mass loss rate, heat release rate, and gas temperatures [14]. The tunnel was $10 \mathrm{~m}$ long with a scale of $1: 20$. The widths used were $0.3 \mathrm{~m}, 0.45 \mathrm{~m}$, and $0.6 \mathrm{~m}$ and the height was varied between $0.25 \mathrm{~m}$ and $0.4 \mathrm{~m}$. Two different types of fuels were used: pools of heptanes and wood cribs. The wood cribs were of three different types. Two were wood cribs with two different porosities and the other one had the laterally placed short pieces of wood replaced by pieces of polyethylene. The velocities tested in the model tunnels were in a range of $0.22 \mathrm{~m} / \mathrm{s}$ to $1.12 \mathrm{~m} / \mathrm{s}$.

\section{Runehamar Tunnel Fire Tests}

Large-scale tunnel tests were carried out with HGV trailer mock-up cargos in the Runehamar tunnel in Norway $[15,16]$. The tunnel is a two lane asphalted road tunnel that was taken out of use and is $1600 \mathrm{~m}$ long, $6 \mathrm{~m}$ high and $9 \mathrm{~m}$ wide, with a slope varying between $0.5-1 \%$. The tunnel was a blasted rock tunnel with a cross-section varying between $47-50 \mathrm{~m}^{2}$.

In total four tests were performed with fire in a HGV trailer mock-up. The specific commodities used consisted of four different materials, each representing a category of material typically found in the cargo of an HGV trailer. These commodities were: standardized wood pallets, plastic pallets made of polyethylene (PE), a standardized test commodity consisting of polystyrene (PS) cups in compartmented cardboard cartons and polyurethane (PUR) mattresses. In three tests mixtures of the various cellulosic and plastic materials were used, and in one test a commodity consisting of furniture and fixtures was used. A polyester tarpaulin covered the cargo in each test. The HGV trailer mock-up was $10.45 \mathrm{~m}$ long, $2.9 \mathrm{~m}$ wide and $4.5 \mathrm{~m}$ high with the trailer floor at $1.1 \mathrm{~m}$ above the road surface.

\section{Benelux Tunnel Fire Tests}

Fourteen large-scale tests were carried out by TNO in the Second Benelux Tunnel in the Netherlands in 2002 [17]. The tunnel has a rectangular cross-section with a height of $5.1 \mathrm{~m}$ and a width of $9.8 \mathrm{~m}$ and a length of about $900 \mathrm{~m}$. The tunnel has a maximum slope of $4.4 \%$ and was equipped with longitudinal ventilation. A total of six jet fans were installed at the upstream portal of the tunnel in order to create air velocities up to $6 \mathrm{~m} / \mathrm{s}$. The test site was located at $265 \mathrm{~m}$ from the downstream portal. Covered truckloads (Tests 8 and 10) were tested under different ventilation conditions. Each truckload consisted of $800 \mathrm{~kg}$ wooden pallets (total of 36 EURO-pallets, 4 piles with 9 pallets in each pile), with four tyres placed on the top. The fire load was mounted on a mockup of a truck with a cover of tarpaulin were the rear end was open. The total length of the mockup was $4.5 \mathrm{~m}$, the width was $2.4 \mathrm{~m}$ and the height was $2.5 \mathrm{~m}$. The longitudinal ventilation was varied between $0 \mathrm{~m} / \mathrm{s}$ to $6 \mathrm{~m} / \mathrm{s}$. In Tests 12 to 14, different sprinkler systems 
were tested for different ventilation rates. In Test 14 no covering was used and the fire load was doubled to $1600 \mathrm{~kg}$ of wooden pallets.

The properties of the fuels used in these tests are summarized in Table 1 for the following analysis.

Table 1. Properties of fuels used in these tests.

\begin{tabular}{|l|c|c|c|c|c|}
\hline Material & $\begin{array}{c}\text { Burning rate } \\
\text { per unit area } \dot{m}_{f}^{\prime \prime} \\
\left(\mathrm{kg} / \mathrm{m}^{2} \cdot \mathrm{s}\right)\end{array}$ & $\begin{array}{c}\text { Heat of } \\
\text { Combustion } \Delta H_{c} \\
(\mathrm{MJ} / \mathrm{kg})\end{array}$ & $\begin{array}{c}\text { Thermal } \\
\text { inertia } k \rho c \\
\left(\mathrm{~kJ} / \mathrm{m}^{4} \cdot \mathrm{s} \cdot \mathrm{K}^{2}\right)\end{array}$ & $\begin{array}{c}\text { Material } \\
\text { property } \\
C_{f}\end{array}$ & $\begin{array}{c}\text { Relevant } \\
\text { tests }\end{array}$ \\
\hline Wood & 0.013 & 16.7 & 0.15 & 1447 & $\begin{array}{c}\text { Runehamar tests, } \\
\text { Benelux tests, } \\
\text { Model scale tests }\end{array}$ \\
\hline PE Plastic & 0.014 & 40.0 & 1.83 & 567 & Runehamar (T1) \\
\hline $\begin{array}{l}\text { PUR } \\
\text { mattresses }\end{array}$ & 0.032 & 25.0 & 0.04 & 20000 & Runehamar (T2) \\
\hline Furniture & 0.020 & 25.0 & 0.15 & 3333 & Runehamar (T3) \\
\hline Polystyrene & 0.035 & 41.9 & 0.58 & 2531 & Runehamar (T4) \\
\hline
\end{tabular}

\section{DISCUSSION OF RESULTS}

Data relevant to the fire growth rate from the above tunnel fire tests were applied to the analysis of the fire growth rate here. The fire growth rates were calculated based on the data in a range of about $20 \%$ to $80 \%$ of the maximum heat release rate in these tests. This means that heat release rate value at $80 \%$ of the maximum heat release rate minus the heat release rate value at $20 \%$ of the maximum heat release rate was divided by corresponding time difference. This means in reality that the fire growth rate is assumed to be linear in this range. The linear trend can be easily seen by observing the measured data.

\section{Effect of Ventilation}

Figure 4 shows how the data of the fire growth rates vary with the ventilation velocity in longitudinal ventilation tests. Clearly, it shows that the fire growth rate increases linearly with the ventilation velocity. This trend complies well with the equation proposed by Thomas. It is also shown that the fire growth rate is nearly three times larger than that in a free-burn test, when the ventilation velocity equals $0.9 \mathrm{~m} / \mathrm{s}$, corresponding to $4.3 \mathrm{~m} / \mathrm{s}$ in full-scale. This means that the ventilation velocity plays a very important role in the fire development. The fire growth rate in a tunnel fire tests is close to that in a free-burn test when the ventilation velocity is equal to $0.3 \mathrm{~m} / \mathrm{s}$. As the fire growth rate is one of the most important design parameters for tunnel safety these results are considered as important.

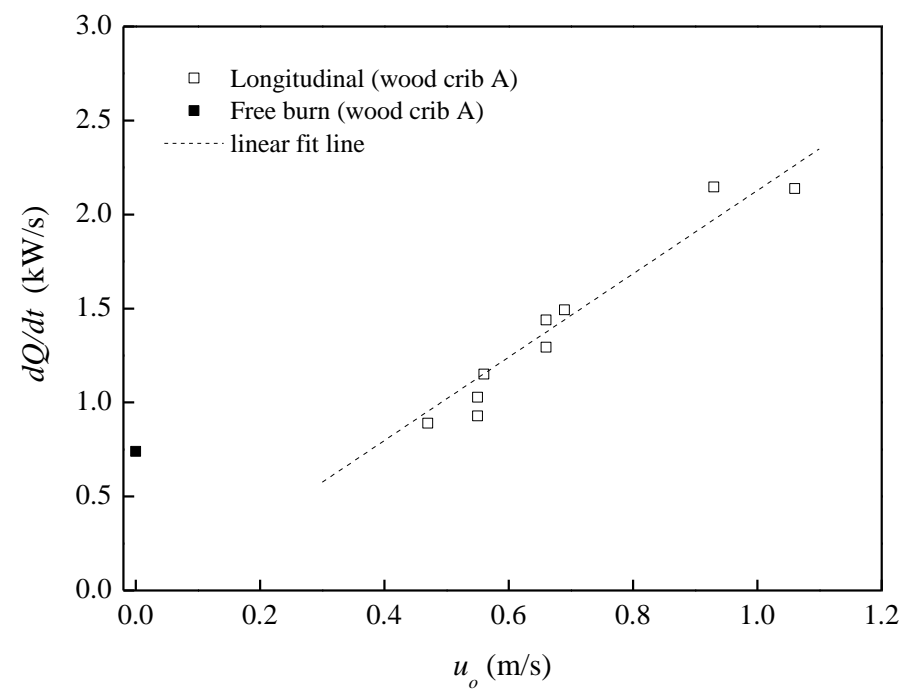

Fig. 4. The fire growth rate as a function of the ventilation velocity. 


\section{Fire Growth Rate}

Figure 5 shows the dimensionless fire growth rates in model scale tunnel fire tests. Clearly, it shows that the proposed line correlates with the tests data well. One datapoint from the extraction ventilation tests at a dimensionless fire growth rate of about 0.6 deviates from the proposed line significantly. The reason may be that the ventilation velocity across the fire source is estimated based on the ventilation system rather than by direct measurement in the point extraction ventilation tests. This means that larger error may be produced in these tests compared to others.

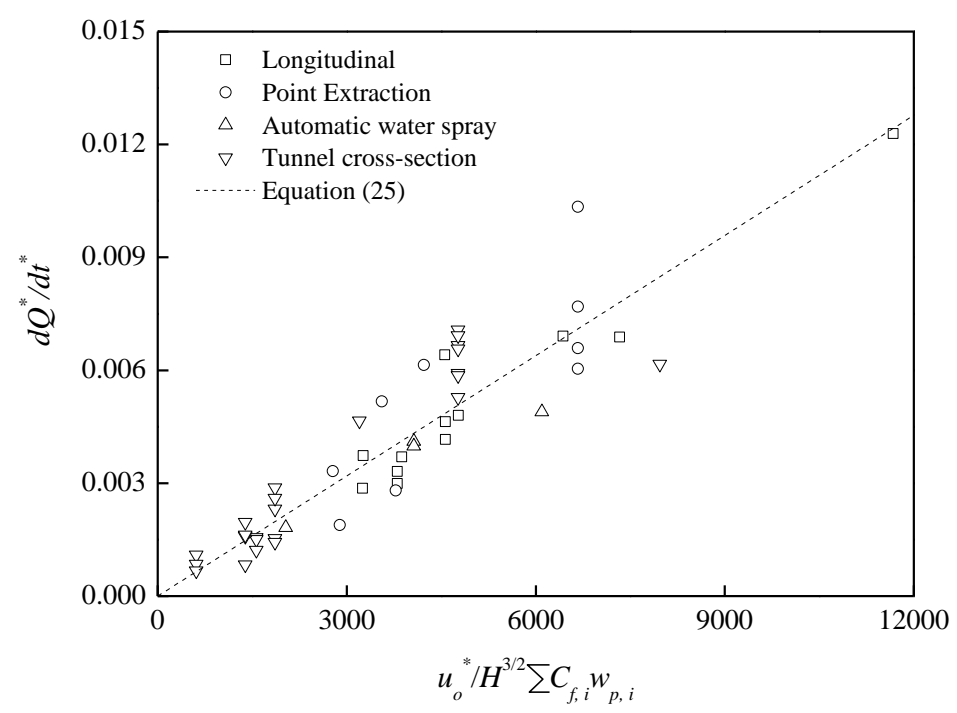

Fig. 5. The dimensionless fire growth rate in model scale tests.

The proposed line in Fig. 5 can be expressed as follows:

$\frac{d Q^{*}}{d t^{*}}=1.1 \times 10^{-6} \frac{u_{o}^{*}}{H^{3 / 2}} \sum_{i=1}^{N} C_{f, i} w_{p, i}$

A correlation coefficient of 0.9165 was found for the above equation. The good correlation proves the earlier assumption that the longitudinal flame spread dominates the flame spread in a tunnel fire.

For practical use, an expression of the fire growth rate, $d Q / d t$, should be more useful than the dimensionless fire growth rate $d Q^{*} / d t^{*}$. Therefore Eq. 22 is written in another form:

$\frac{d Q}{d t}=1.2 \times 10^{-3} u_{o} \sum_{i=1}^{N} C_{f, i} w_{p, i}$

For wood fires, the fire growth rate in a ventilated tunnel can be approximately expressed as:

$\frac{d Q}{d t}=1.8 w_{p} u_{o}$

\section{Comparison with Full-Scale Tests}

Data from the Runehamar tunnel fire tests and Benelux tunnel fire tests were used here to verify the proposed Eq. 22, and further to verify the method of predicting the fire growth rate for fuels consisting of several parts. 
Figure 6 shows the comparison of the fire growth rates in the Runehamar tunnel fire tests and Benelux tunnel fire tests with the model scale tests. According to Eq. 18, each material corresponds to one material property $C_{f, i}$. The wet perimeter of the $i^{\text {th }}$ fuel $w_{p, i}$ is estimated by the contact perimeter in one cross-section between the $i^{\text {th }}$ fuel and the air flow.

In Runehamar Test 1 (T1), the fuel consisted of wood pallets and plastic pallets. In Test 2, the fuel consisted of wood pallets and PUR mattresses. In Test 3, the fuel mainly consisted of furniture. In Test 4, the fuel consisted of plastic cups in cardboard boxes on wood pallets. Since the outside cardboard was burned out after a while, it is difficult to estimate the wet perimeter of the fuel in this test and also the material property. A weighted average was used to estimate the material property here. The fuels used in the Benelux tests T8, T10 and T14 are all wood pallets.

The results in Fig. 6 show that the data from the Runehamar tunnel fire tests and the Benelux tunnel fire tests comply well with the data from the model-scale tests and Eq. 22. This indicates that the fire growth rate can be scaled appropriately in model-scale tests even with a scaling ratio of about 1:20. Further, it proves that Eq. 22 is applicable to predict the fire growth rate for different types of fuels, even for fuels consisting of several parts.

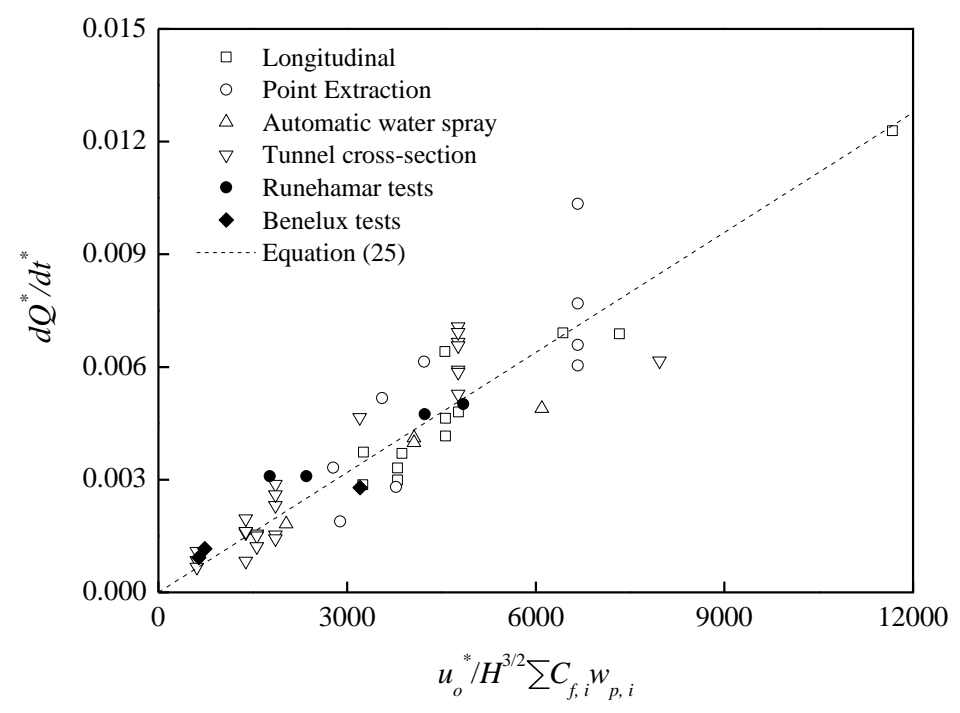

Fig. 6. Comparison of data from full scale tests with the model scale tests.

\section{CONCLUSION}

A simple theoretical model of the fire growth rate in a ventilated tunnel fire was proposed. The relationship between the flame spread and the fire growth rate in a ventilated flow was analyzed theoretically. A large amount of data relevant to the fire growth rate from model and full-scale tunnel fire tests was collected and applied to a detailed analysis of the effect of ventilation on the fire growth rate.

The longitudinal flame spread dominates the flame spread in a tunnel fire. The thermal inertia, heat of combustion, the wet perimeter, and the mass burning rate per unit area of the fuel play important roles in the fire growth rate. In addition, the fire growth rate increases linearly with the ventilation velocity. A robust equation, i.e. Eq. 25 or Eq. 26 , that fits all the data of the fire growth rate from model and full-scale tunnel fire tests very well was proposed. Further, the proposed equation is applicable to predict the fire growth rate for different types of fuels, even for fuels consisting of several parts. However, additional tests results with ventilation velocities over $8 \mathrm{~m} / \mathrm{s}$ in full-scale should be valuable to identify the transition conditions under which the cooling effect starts to dominate.

The results of this paper should be applicable to other ventilated fires, such as vehicle fires in the open under strong wind, in which the longitudinal fire spread also dominates the combustion process. This method of predicting the fire growth rate can also be applied to some other scenarios, such as rack storage 
fires, in which the dominating term is probably the vertical fire spread in an introduced vertical flow due to depletion of oxygen and buoyancy of the flame and hot gases.

\section{ACKNOWLEDGEMENT}

The study was sponsored by SP Tunnel and Underground Safety Centre which is gratefully acknowledged.

\section{REFERENCES}

[1] Oka, Y., Atkinson, G.T., (1995) Control of Smoke Flow in Tunnel Fires, Fire Safety Journal 25: 305-322, http://dx.doi.org/10.1016/0379-7112(96)00007-0

[2] Wu, Y., Bakar, M.Z.A., (2000) Control of Smoke Flow in Tunnel Fires using Longitudinal Ventilation Systems-a Study of the Critical Velocity, Fire Safety Journal 35: 363-390, http://dx.doi.org/10.1016/S0379-7112(00)00031-X

[3] Li, Y.Z., Lei, B., Ingason, H., Study of Critical Velocity and Backlayering Length in Longitudinally Ventilated Tunnel Fires, Fire Safety Journal 45(6-8): 361-370, http://dx.doi.org/10.1016/j.firesaf.2010.07.003

[4] Carvel, R.O., Beard, A.N., and Jowitt, P.W., "The Effect of Forced Longitudinal Ventilation on a HGV Fire in a Tunnel," Proceedings of the International Conference on Tunnel Fires and Escape from Tunnels, Lyon, France, 5-7 May, 1999, pp. 191-199.

[5] Drysdale, D., An Introduction to Fire Dynamics ( $\left.2^{\text {nd }} e d\right)$, John Wiley \& Sons, Chichester, 1999.

[6] Thomas, P.H., (1971) Rates of Spread for some Wind-Driven Fires. Forestry, 44(2): 155-175, http://dx.doi.org/10.1093/forestry/44.2.155

[7] Quintiere, J.G., "Surface Flame Spread," The SFPE Handbook of Fire Protection Engineering (3 ${ }^{\text {rd }}$ ed), DiNenno P.J. (ed.), National Fire Protection Association, Quincy, MA, 2002, p. 2/12.

[8] Tewarson A., Pion, R.F., (1976) Flammability of Plastics. I. Burning intensity, Combustion and Flame 26: 85-103, http://dx.doi.org/10.1016/0010-2180(76)90059-6

[9] Ingason, H. and Li, Y.Z., (2010) Model Scale Tunnel Fire Tests with Longitudinal Ventilation, Fire Safety Journal 45(6-8): 371-384, http://dx.doi.org/10.1016/j.firesaf.2010.07.004

[10] Quintiere, J.G., (1989) Scaling Applications in Fire Research, Fire Safety Journal 15: 3-29, http://dx.doi.org/10.1016/0379-7112(89)90045-3

[11] Li, Y.Z., Ingason, H., "Model Scale Tunnel Fire Tests with Automatic Water Spray System," SP Report 2010:61, SP Technical Research Institute of Sweden, Borås, Sweden, 2010, 83 p.

[12] Ingason, H., and Li, Y.Z., (2010) Model Scale Tunnel Fire Tests with Point Extraction Ventilation. Journal of Fire Protection Engineering, http://dx.doi.org/10.1177/1042391510394242

[13] Ingason, H. and Li, Y.Z., "Mode Scale Tunnel Fire Tests with Point Extraction Ventilation," SP Report 2010:03, SP Technical Research Institute of Sweden, Borås, Sweden, 2010, 72 p.

[14] Lönnermark, A., Ingason, H., The Effect of Cross-sectional Area and Air Velocity on the Conditions in a Tunnel during a Fire, SP Report 2007:05, SP Technical Research Institute of Sweden, Borås, Sweden, 2007, 92 p.

[15] Ingason, H., and Lönnermark, A., (2005) Heat Release Rates from Heavy Goods Vehicle Trailers in Tunnels, Fire Safety Journal, 40: 646-668, http://dx.doi.org/10.1016/j.firesaf.2005.06.002

[16] Lönnermark, A., and Ingason, H., (2006) Fire Spread and Flame Length in Large-Scale Tunnel Fires, Fire Technology, 42: 283-302, http://dx.doi.org/10.1007/s10694-006-7508-7

[17] Lemaire, A., Van de Leur, P.H.E., and Kenyon, Y.M., "Safety Proef: TNO Metingen Beneluxtunnel - Meetrapport", TNO, TNO-Rapport 2002-CVB-R05572, 2002, 218 p. 